\title{
Masalah Tongkat Dan Tali Dengan Panjang Tali Melebihi Setengah Lingkaran
}

\author{
Mans Lumiu Mananohas ${ }^{1 *}$, Charles Efraim Mongi ${ }^{2}$ \\ ${ }^{1,2}$ Program Studi Matematika, Fakultas Matematika dan Ilmu Pengetahuan Alam, \\ Universitas Sam Ratulangi Manado \\ *corresponding author email: mansmananohas@yahoo.com
}

\begin{abstract}
Abstrak
Sebuah tali dengan panjang tertentu dengan kedua ujungnya diikatkan tepat pada kedua ujung sebuah tongkat lurus. Akan dicari bentuk tali yang memaksimumkan luas antara tali dan tongkat. Solusi yang diinginkan disini adalah kurva berbentuk fungsi $x=f(t)$. Agar dapat disajikan lebih sederhana masalah ini akan di bahas dengan asumsi panjang tongkat 1 satuan. Untuk $1<l \leq \pi / 2$, telah ditemukan solusinya, yaitu bentuk tali haruslah berupa segmen lingkaran yang berpusat di garis $t=1 / 2$. Akan tetapi sampai saat ini untuk kasus $l>\pi / 2$ belum ditemukan solusinya. Untuk menyelesaikan kasus ini telah banyak upaya yang dilakukan . Meskipun belum mencapai hasil akhir yang diinginkan, akan tetapi usaha-usaha yang dilakukan telah melahirkan beberapa kesimpulan penting, diantaranya telah berhasil disimpulkan bahwa untuk kasus $l>\pi / 2$ masalah tongkat dan tali tidak mempunyai ekstremum patah (turunannya tidak kontinu di sejumlah hingga titik). Dalam penelitian ini juga telah ditemukan batasan bagi luas yang mungkin dapat dibentuk oleh tongkat dan tali.
\end{abstract}

Kata kunci: Kalkulus Variasi, setengah lingkaran, masalah Dido, maksimum.

\section{On The Stick And Rope Problem With Length Of The Rope Greater Than Semicircle}

\begin{abstract}
A rope with a certain length with both ends tied precisely at both ends of a straight stick. We will seek for the shape of the rope that maximizes the area between the rope and the stick. Preferred solution here is the curve is a function $x=f(t)$. In order to more simply, we present this issue with the assumption that the length of the stick is 1 unit. For the length of the rope $1<l \leq \frac{\pi}{2}$, the solution have found, the shape of the rope should be a segment of a circle centered on the line $t=\frac{1}{2}$. But until now to the case $l>\frac{\pi}{2}$ has not found a solution. To solve this case, many efforts have done. Although not yet reached the desired end result, but the efforts was give some important conclusions, including the conclution that for the case $l>\frac{\pi}{2}$ issues sticks and ropes did not have ekstremum broken. In this study we found the relation between the length of the rope and the area that we present in an inequality.
\end{abstract}

Key words: Variational Calculus, semicircle, Dido problem, maximum.

\section{Pendahuluan}

Sebuah tali dengan panjang tertentu dengan kedua ujungnya diikatkan tepat pada kedua ujung sebuah tongkat lurus. Akan dicari bentuk tali yang memaksimumkan luas antara tali dan tongkat. Solusi yang diinginkan disini adalah kurva berbentuk fungsi $x=f(t)$. Masalah ini merupakan pengembangan dari masalah Dido [3, 4], perbedaannya adalah dalam masalah Dido kurvanya tidak harus sebuah fungsi satu variabel, sementara masalah ini mensyaratkan kurva solusi harus berupa fungsi 1 variabel. Berdasarkan [2], dengan alasan agar dapat disajikan lebih sederhana masalah ini akan di bahas dengan asumsi panjang tongkat 1 satuan. Untuk $1<l \leq \frac{\pi}{2}$, telah ditemukan solusinya, yaitu bentuk tali haruslah berupa segmen lingkaran yang berpusat di garis $t=\frac{1}{2}$. Akan tetapi sampai saat ini untuk kasus $l>\frac{\pi}{2}$ belum ditemukan solusinya. Untuk menyelesaikan kasus ini telah banyak upaya yang dilakukan . Meskipun belum mencapai hasil akhir yang diinginkan, akan tetapi usahausaha yang dilakukan telah melahirkan beberapa kesimpulan penting, diantaranya telah berhasil 
disimpulkan bahwa untuk kasus $l>\frac{\pi}{2}$ masalah tongkat dan tali tidak mempunyai ekstremum patah [1] . Dalam penelitian ini juga telah ditemukan batasan bagi luas yang mungkin dapat dibentuk oleh tongkat dan tali.

\section{Formulasi Masalah}

Permasalahan ini dapat disederhanakan dalam interval satuan $I=[0,1]$. Asumsikan $x: I \rightarrow R$ adalah fungsi $C^{2}$ yang merupakan representasi kurva yang dibentuk oleh tali dan harus memenuhi $x(0)=0, x(1)=0$. Syarat terakhir ini akan menjamin bahwa setiap ujung tali masing-masing berada tepat pada kedua ujung tongkat. Asumsikan juga $x(t) \geq 0$ untuk semua $t \in I$. Jadi, luas daerah yang dibatasi oleh kurva $x$ dan interval satuan $I$ adalah

$$
A[x]=\int_{0}^{1} x(t) d t
$$

Demikian juga panjang kurva $x$ disepanjang interval satuan $I$ adalah

$$
L[x]=\int_{0}^{1} \sqrt{1+\dot{x}^{2}} d t
$$

Jika panjang tali diberikan, sebut $l$, maka dapat didefinisikan sebuah fungsional baru

$$
\bar{L}[x]=L[x, \dot{x}]-l
$$

Apabila kurva $x$ merupakan solusi, maka haruslah dipenuhi kondisi

dan nilai

$$
\bar{L}[x]=\int_{0}^{1}\left(\sqrt{1+\dot{x}^{2}}-l\right) d t=0
$$

$$
A[x]=\int_{0}^{1} x(t) d t
$$

mencapai maksimum. Jadi, inti dari permasalahannya adalah mencari bentuk tali dengan panjang $l$ yang setiap ujungnya diikatkan tepat pada kedua ujung tongkat sedemikian sehingga daerah yang dibentuk oleh tali dan tongkat memiliki luas terbesar.

\section{Hasil dan Pembahasan}

\subsection{Ketaksamaan pada Masalah Tongkat dan Tali}

Teorema

Misalkan $A$ adalah luas daerah yang dibentuk antara tali dan tongkat. Jika $l=\frac{\pi}{2}+a$ dan $a>0$, maka $A<\frac{4 a+\pi}{8}$.

Bukti

Perhatikan Gambar 1

Misalkan $A$ adalah luas daerah yang dibentuk antara tali (kurva $x$ ) dan tongkat (sumbu horisontal antara $t=0$ dan $t=1$ ). Tulis $A=A_{0}+A^{\prime}$.

Selanjutnya, bagi $A$ dengan garis $x=k$ sedemikian sehingga panjang kurva yang membentuk $A_{0}$, sebut $x_{0}$, adalah $\frac{\pi}{2}$

Akibatnya, berdasarkan solusi masalah isoperimetrik pada setengah bidang $2 \mathrm{D}$,

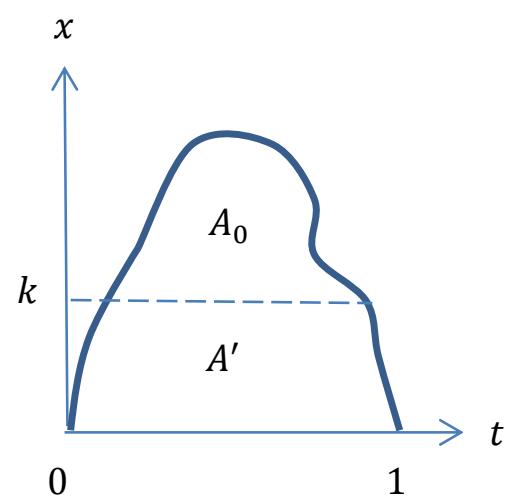

Gambar 1. Daerah yang dibentuk antara tali dan tongkat 
diperoleh bentuk geometri dengan luas optimal yang dibentuk antara kurva $x_{0}$ dan garis $x=k$ adalah setengah lingkaran yang jari-jarinya $\frac{1}{2}$, sehingga berlaku

$$
A_{0} \leq \frac{\pi}{8}
$$

Adapun solusi yang diinginkan disini berupa kurva kontinu yang dapat direpresentasikan sebagai fungsi $x=f(t)$. Selanjutnya, karena kekontinuan dari kurva $x$, maka haruslah dipenuhi $k<\frac{a}{2}$. Akibatnya diperoleh

$$
A^{\prime}<k .1=k<\frac{a}{2}
$$

Akhirnya, berdasarkan (1) dan (2) diperoleh ketaksamaan

Jadi, teorema diatas terbukti.

$$
A<A_{0}+A^{\prime}=\frac{\pi}{8}+\frac{a}{2}=\frac{4 a+\pi}{8}
$$

\subsection{Tinjauan Lain dari Kasus Khusus Panjang Tali 2 Satuan}

Dalam pembahasan secara umum kasus masalah tongkat dan tali, telah diperoleh suatu persamaan lingkaran:

$$
\left(x-C_{2}\right)^{2}+\left(t-C_{1}\right)^{2}=\lambda^{2}
$$

Selanjutnya pada [1], dengan mengeluarkan variabel $x$ secara ekspilisit dari persamaan lingkaran diatas kemudian mensubstitusinya ke integral panjang kurva diperoleh:

$$
l=\int_{0}^{1} \sqrt{1+\frac{\left(t-C_{1}\right)^{2}}{\lambda^{2}-\left(t-C_{1}\right)^{2}}} d t=\int_{0}^{1} \sqrt{\frac{\lambda^{2}}{\lambda^{2}-\left(t-\frac{1}{2}\right)^{2}}} d t=\int_{0}^{1} \sqrt{\frac{1}{1-\left(\left(t-\frac{1}{2}\right) / \lambda\right)^{2}}} d t
$$

Dengan memisalkan $u=\frac{\left(t-\frac{1}{2}\right)}{\lambda}$ persamaan diatas menjadi

$$
l=\lambda \int_{-1 / 2 \lambda}^{1 / 2 \lambda} \sqrt{\frac{1}{1-u^{2}}} d u=\lambda\left[\sin ^{-1} u\right]_{-1 / 2 \lambda}^{1 / 2 \lambda} .
$$

Sehingga diperoleh $l=2 \lambda \sin ^{-1}(1 / 2 \lambda)$ atau

$$
\sin \left(\frac{l}{2 \lambda}\right)=\frac{1}{2 \lambda}
$$

dimana $\lambda$ adalah jari-jari lingkaran, dengan $|\lambda| \geq \frac{1}{2}$. Dengan kata lain apabila $l=2$, untuk memperoleh bentuk tali yang memaksimumkan luas antara tongkat dan tali maka haruslah terlebih dahulu menyelesaikan persamaan:

$$
\sin \left(\frac{1}{\lambda}\right)=\frac{1}{2 \lambda}
$$

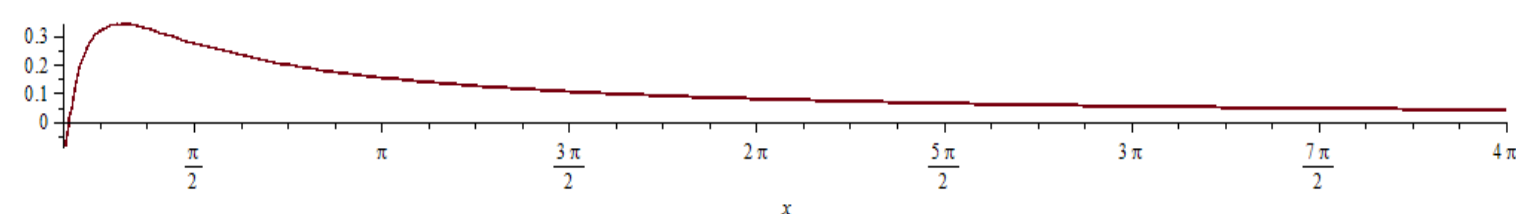

Gambar 2 Plot kurva dari persamaan (1) untuk $\lambda=\left[\frac{1}{2}, 4 \pi\right]$

Perhatikan pada Gambar 2, dengan bantuan program Maple, diperoleh kisaran nilai 0,5 $<\frac{687 \pi}{4096}<$ $\lambda<\frac{687 \pi}{4096}$, artinya apabila memang nilai $\lambda$ memenuhi solusi masalah tongkat dan tali untuk kasus $l=$ 2 , maka haruslah merupakan segmen lingkaran dari sebuah lingkaran dengan jari-jari lebih dari 0,5 dimana panjang segmen diatas sumbu $x$ lebih pendek dari panjang segmen di bawah sumbu $x$. Perhatikan bahwa keliling yang mungkin dibentuk adalah 


$$
K<2 \pi\left(\frac{687 \pi}{4096}\right) \approx 3,307
$$

Berdasarkan syarat batas, yakni kurva solusi harus melalui $(0,0)$ dan $(1,0)$, maka jelas panjang segmen lingkaran yang terletak di atas sumbu $x$ harus kurang dari 2. Jadi, dapat disimpulkan bahwa untuk kasus panjang tali 2 satuan segmen lingkaran bukan lagi solusi.

\section{Kesimpulan}

Penelitian ini telah memberikan hasil berupa batasan bagi solusi masalah tongkat dan tali dengan kasus panjang tali lebih panjang dari setengah lingkaran satuan. Batasan ini disajikan dalam bentuk ketaksamaan yang nantinya bisa dipakai untuk mengidentifikasi kurva-kurva kandidat solusi pada kasus panjang tali lebih panjang dari setengah lingkaran satuan. Untuk penelitian selanjutnya, akan sangat mungkin batasan (batas atas dari luas yang dibentuk antara sumbu-x dan kurva solusi).

\section{Daftar Pustaka}

[1] Mananohas, M. dan Pranoto, I. 2013, More Results On The Stick and Rope Problem. Prosiding ICOWOBAS. UTM, Malaysia. Hal 226-229.

[2] Mananohas, M. dan Pranoto, I. 2013, Masalah Tali dan Tongkat. Prosiding Seminar Nasional IT dan Sains. UNSRAT, Manado. Hal 52-57.

[3] Blasjo, V. 2005. The evolution of the isoperimetric problem. The American Mathematical Monthly, Vol. 112 Mathematical Association of America. Hal 526-566.

[4] Tapia, R. 2012. The isoperimetric problem revisited: Extracting a short proof of sufficiency from Ruler's 1744 Proof of necessity. Diseminarkan pada SIAM Annual Meeting in Minneapolis, Minnesota. 